\title{
MANICA, Daniela; KOFES, Suely. 2015. Vida e grafias: narrativas antropológicas, entre biografia e etnografia. Lamparina. 412 pp.
}

\author{
FELIPE MAGALDI
}

A crítica da resistente oposição entre indivíduo e sociedade tem ocupado o cerne dos debates antropológicos contemporâneos. Seus contornos mais nítidos se delineiam sobretudo nos campos da etnologia indígena e da antropologia da ciência e da tecnologia, nos quais associam-se a toda uma série de questionamentos a propósito da tentativa de separação entre natureza e cultura protagonizada pelos saberes ocidentais modernos. Entretanto, o adensamento do debate nessas áreas de investigação não implica em sua restrição ao estudo das sociocosmologias ameríndias ou das práticas de laboratório. Pelo contrário, é também crescente o número de pesquisas comprometidas com a reformulação dos dualismos historicamente estabelecidos na antropologia em searas cada vez mais transversais e heterogêneas, confirmando tanto a relevância dessa incumbência quanto a criatividade e a disposição da disciplina de levar a sério o projeto de simetrizar seus campos empíricos.

É o caso do livro Vida e grafias: narrativas antropológicas, entre biografia e etnografia, organizado por Suely Kofes e Daniela Manica. Surgido na esteira das referidas preocupações, a obra traz a originalidade de eleger como seu fio condutor privilegiado as articulações possíveis entre etnografia e biografia. Mais especificamente, sua aposta reside na problematização dos desafios da questão da escrita no ofício antropológico a partir do que se poderia caracterizar como uma dupla tarefa: por um lado, a desestabilização dos pressupostos do fazer biográfico, tais como a "individualidade", o "self", o "sujeito", a "coerência da vida" etc.; e por outro, ao mesmo tempo, a apropriação de suas intenções no intuito de engendrar narrativas capazes de dar conta da abordagem de trajetórias em sua complexidade e extensão. Longe de paradoxal, o que essa proposta enseja é uma espécie de terreno de contágio crítico e controlado - entre etnografia e biografia, tendo em vista suas mútuas afecções, mas sem diluir suas especificidades.

Trata-se de uma coletânea composta por dezessete artigos, produto do Grupo de Trabalho Etnografia e Biografia na Antropologia: Experiências com as Diversas Grafias sobre a Vida Social, coordenado pelas autoras na 28 Reunião Brasileira de Antropologia, realizada em 2012 na Pontifícia Universidade Católica de São Paulo. De modo geral, os trabalhos incluem em seu escopo tanto reflexões metodológicas sobre as fontes possíveis para essa linha de investigação (incluindo-se aí as próprias obras "biográficas" ou "autobiográficas", em combinação com arquivos, documentos, imagens, sons, 
trabalho de campo e entrevistas, entre outros recursos) quanto questões mais teóricas, desenvolvidas como base no estudo de autores situados.

Os skatistas são os primeiros viventes a figurar no livro. Em um pequeno e provocativo prefácio, de autoria de Pedro Peixoto Ferreira, deixa-se entrever a questão que permeia toda a obra: o problema da "grafia", suscitado a partir do caso da "skatografia". Trata-se das variadas formas de escrita do skate, envolvendo seus corpos e obstáculos, assim como toda uma variada produção fotográfica, videográfica e textual. Apoiado nessas imagens e discursos, o autor ganha acesso ao complexo conceito nativo de "pico" (e, por derivação, de "picologia"), que diz respeito à busca ativa de uma configuração específica de espaço-tempo na qual a prática do skate se torna possível e desejável. Surgem, então, as principais questões que ecoarão nas páginas seguintes. Como se entrelaçam e se co-constituem as pessoas e as coisas? E, nessa trama, como se imbricam os diferentes tipos de grafia?

A apresentação, assinada pelas autoras, faz menção ao texto usado como chamada para resumos, contribuindo para elucidar as intenções iniciais do debate. A proposta de Tim Ingold de que a antropologia deva ser uma indagação sobre as condições de possibilidade da vida humana no mundo, e não um estudo autocentrado sobre como se escreve etnografia, revela-se aí insuficiente. Diversamente, busca-se aceitar os desafios da grafia na antropologia, entendendo-os não como "autocentrados", mas elementares. Isso porque a seara aberta através dessa escolha envolve ainda uma investigação a propósito das múltiplas formas de grafia, não só aquela antecedida pelo prefixo "etno". A "biografia" se destaca dessa intenção, acrescentando-se, porém, à autobiografia, à fotografia, à cartografia e às distintas formas de registros, textuais, imagéticos e sonoros.

O artigo "Narrativas biográfica: que tipo de antropologia isso pode ser?", de Suely Kofes, aprofunda ainda mais essas indagações, dispondo-se a retomar, de forma inovadora, a clássica questão das "histórias de vida" - já consolidada como "método qualitativo" nos manuais de pesquisa etnográfica - a partir de um enfoque biográfico (que poderia ser também caracterizado como "etnobiográfico"). Isso significa tensionar os supostos antropológicos de totalidade, tais como "sociedade", "cultura”, "estrutura", comprometidos com o controverso horizonte de comparação, generalização e universalismo característico da disciplina, cujo efeito é encontrar na particularidade (sendo a etnografia uma de suas formas) ora um fim em si mesma, ora apenas uma parte de um objetivo comparativo mais amplo. Ademais, implica em contornar o malabarismo semântico que fez coincidir o termo "vida", constitutivo do léxico "biografia', com o significado de "indivíduo". Percorrendo a história da antropologia, Kofes trata de demonstrar como o problema das narrativas de e sobre pessoas particulares foi relegado ora ao campo da memória, ora ao campo do psicologismo e da ficção, em oposição à dimensão dos "fatos". Nesse sentido, para reinseri-las plenamente no campo de indagações antropológicas, seria necessário reestabelecer não um individualismo metodológico, mas as próprias distinções entre "particular" e "geral", "ideográfico" e "nomotético, "pesquisa" e "teoria”, em favor de um modelo de análise capaz de dar conta de como os sujeitos são constituídos de relacionamentos, ao mesmo tempo os engendrando. Nesse projeto, uma determinada noção de "experiência" poderia desempenhar um papel chave, na medida em que reconheceria o imbricamento incontornável entre o narrado e o vivido. 
Essas interrogações se verificam com especial clareza em alguns dos artigos subsequentes. Em "Autobiografias, memoriais e a narrativa biográfica de um cientista", Daniela Manica trata do caso do médico baiano Elsimar Coutinho, conhecido por seus experimentos com a saúde reprodutiva da mulher. A partir do entrecruzamento entre suas notas autobiográficas e pesquisas em arquivos de instituições que se envolveram sua trajetória, entre outros recursos metodológicos, a autora busca elucidar a justaposição de contextos sociais que a atravessam, consubstanciadas em um conjunto de relações entre pessoas, instituições, políticas e substâncias. Nesse sentido, sublinha que tomar uma trajetória como fio condutor não implica simplesmente em um foco privilegiado sobre a singularidade de um indivíduo. Em uma arguta revisão bibliográfica, deixa ainda claro as insuficiências das soluções objetivistas instituídas nas ciências sociais para o estudo das trajetórias, particularmente aquela que subjaz à teoria do campo de Pierre Bourdieu, a qual termina submetendo-se aos pressupostos de "verdade" em oposição à “artificialidade”, esbarrando ainda em questões relativas à autoridade etnográfica.

Por um lado, alguns textos dedicam-se a elucubrar a questão do biográfico desde o próprio pensamento antropológico. É exemplo "Escrita de si, escrita do mundo: Michel Leiris e a experiência sagrada”, de Júlia Goyatá, que trata da importância da imbricação entre escrita autobiográfica e teoria social para a fabulação do conceito de "sagrado" nesse autor. Já "Imbricamentos entre etnografia e biografia: um estudo sobre Roy Wagner", de Iracema Dulley, analisa os textos do antropólogo estadunidense no intuito de iluminar as relações entre biografia e etnografia, fazendo menção também a seu próprio contato pessoal com o mesmo (propondo assim, de maneira estimulante, uma "etnografia do autor"). Em "Para além das vidas de Nimuendaju: constituição de narrativas da história da antropologia”, de Christiano Tambascia, a questão reside mais em examinar as narrativas constituídas em torno da carreira desse antropólogo alemão, na intenção de entender os sentidos atribuídos à sua obra na antropologia brasileira.

Avançando ainda mais nos limites da antropologia, encontra-se "Entre negócios, ócios e domingos: a ego-história de Boris Fausto", de Wilton Silva, dedicado à discussão do conceito de ego-história (que condensa a maneira através da qual os historiadores pensam e fazem autobiografia) a partir do exame da obra de Boris Fausto. "Antropologia nas cidades em grafias literárias", de Cristina Maria da Silva, trata das conversações entre a etnografia e a literatura com foco em variados escritores brasileiros contemporâneos especializados na temática urbana. Propondo uma interlocução com a filosofia de autores como Deleuze e Guattari, "Etnografia, cartografia e devir: potencialidades da escrita nas pesquisas antropológicas contemporâneas", de Rafael Mejía, se indaga sobre os desafios da etnografia e da relação entre pesquisa de campo e escritura a partir da aproximação com as cartografias, sugerindo a experimentação e as afecções como pontos de adensamento de seus questionamentos. Em interseção com o campo da política, "Messianismo no neonazismo estadunidense: a autobiografia de David Lane", de Adriana Dias, explora a relação entre experiência, narrativa e memória com base na análise da autobiografia do líder neonazista David Lane. O diálogo com o cinema fica evidente em "Edifício Master: o documentário e a experiência de vida na metrópole”, de Ana Lúcia Modesto, em que se evidencia a sugestão de pensar o levantamento de histórias de vida através dos recursos do documentário, com inspiração no trabalho do diretor Eduardo Coutinho. Há, ainda, uma relação com a música, nítida no 
artigo "Ninguém canta para ninguém: papel da canção, canção de papel”, de Carolina Rodrigues, que se ocupa da crítica aos modos predominantes de apreensão da canção na historiografia, na sociologia da indústria musical, na pedagogia política e nas biografias propriamente ditas.

Como já fica notório nesses dois últimos trabalhos, nem só as vidas dos intelectuais habitam as entrelinhas desta antologia. Destaca-se, igualmente, toda uma série de pesquisas dedicada ao estudo das vidas ordinárias, mais ou menos célebres, porém não menos interessantes. "Por uma etnografia dos artistas populares: reflexões sobre personas midiáticas e biografias de celebridades", de Raphael Bispo, encontra-se justamente nesse limiar, abordando a trajetória da chacrete Índia Potira, valendo-se, para tanto, das narrativas contidas em matérias jornalísticas pesquisadas no acervo da Biblioteca Nacional, assim como da coleção particular da própria artista sobre sua carreira. "Biografias judiciárias: analisando laudos psiquiátricos de autos de processos penais", de Maria Luisa Scaramella, examina o caso psiquiátrico de Maura Lopes Cansado, acusada de estrangular uma paciente durante seu período de internação. A autora, atravessando sua autobiografia e os laudos inscritos nos autos de seu processo penal, questiona a produção de verdade da narrativa biográfica judiciária. "Não mais somente na rua: autobiografia e relatos biográficos de Esmeralda Ortiz como exercício etnográfico em São Paulo", de Hugo Ciavatta, apresenta o caso da ex-moradora de rua Esmeralda Ortiz, partindo de trabalho de campo e também da análise de sua autobiografia na cidade de São Paulo. "Histórias e narrativas envolvendo a ocupação Mauá", de Stella Paterniani, consiste em uma etnografia dos movimentos de moradia envolvidos na ocupação Mauá, também na capital paulista. "Entre relatos de vida, fotografias e cartografias: uma etnografia em diferentes proximidades", de Cristiane Souza, investiga o caso da migrante Dona Elizete entre o interior da Bahia e Salvador, refletindo sobre os usos e possibilidades de diferentes fontes e grafias, bem como acerca da relação entre memória, experiência vivida e território. Finalmente, "Fotografia como resíduo biográfico: memória familiar, cultura urbana e sociabilidade", de Alexandre Bispo, explora uma misteriosa coleção de fotografias familiares encontrada em um antiquário, centrando-se no caso de Cleonice Maria Heine, figura recorrente nesse material. Nesse sentido, busca restituir, assente no estudo das imagens desse arquivo pessoal, sua trajetória em articulação com a cultura urbana de São Paulo por volta das décadas de 1920 e 1960.

Vê-se, a partir da leitura desses trabalhos, as potenciais direções apontadas pela proposta do livro. Em primeiro lugar, destaque-se a investigação sobre conceitos que tensionam a díade vida-grafia, evidente sobretudo nos artigos que evocam autores como Leiris, Bataille, Deleuze e Guattari, entre outros. Em seguida, evidencia-se o estudo de itinerários que, apenas aparentemente "individuais", terminam por revelar complexas tramas de pessoas, instituições e materialidades, sem submetê-las ao estatuto de uma sociedade englobante (no sentido durkheimiano). É o caso das pesquisas sobre Elsimar Coutinho, Roy Wagner, David Lane, Índia Potira, Esmeralda Ortiz, Maura Lopes Cansado, Dona Elizete, Cleonice Maria Heine, etc. O sentido inverso, destaque-se, é igualmente verdadeiro. Assim, em pesquisas como aquela sobre os grupos engajados na ocupação Mauá, a significação do “coletivo" não é estabelecida meramente na ordem do supra-individual, mas na coexistência entre coesão e diferenciação.

Ademais, chama a atenção a reflexão sobre os usos metodológicos da escrita, seja ela escrita "de si" - como nos artigos que operam sobretudo a partir de autobiografias -ou "do outro" - como no 
caso das pesquisas que se dedicam a narrativas históricas e laudos judiciários. Encontram-se, como exemplos, as trajetórias de Elsimar Coutinho, David Lane, Esmeralda Ortiz, Índia Potira, Nimuendaju e Maria Lopes Cansado. Questiona-se, nesses textos, a dualidade entre o estatuto de verdade e/ou de ficção implicados nessas narrativas. Finalmente, a própria coincidência entre "escrita" e "grafia" é posta sob suspeita nas investigações que se engajam na análise de outras linguagens, artísticas ou não. Nesse filão, avultam os textos sobre o documentário Edifício Master, sobre os registros da música popular e sobre os casos de Cleonice Heine e de Dona Elizete, construídos essencialmente a partir de recursos imagéticos e fotográficos ou da combinação destes com fontes de outra ordem. A própria literatura aparece nesse corpo textual ultrapassando os limites da mera representação gráfica, coincidindo com a dimensão da experiência.

Pode-se afirmar que não é somente a "vida" de uma série de personagens que se encontra inscrita nesta compilação. Também faz-se presente, em surdina, a própria questão ontológica sobre o que é vida ou sobre o que conta como vida, isto é, o estatuto próprio da bios, em suas várias formas de registro. Embora sem dar respostas definitivas para esse problema, Vida e Grafias deixa uma pista interessante, justamente porque mais sutil: aquela segundo a qual onde há um nome, há um conjunto de relações. Como sugere o posfácio de Fabiana Bruno, é preciso aceitar que toda e qualquer biografia encerra tanto o singular como o coletivo. Seria possível admitir, assim, a relacionalidade - mais que o relativismo como a possível chave para o entendimento do enigma etnobiográfico. Por esse motivo, e por contar com trabalhos de alta qualidade, trata-se aqui de uma leitura inspiradora e fundamental, especialmente para aqueles pesquisadores que estejam comprometidos com a busca de novas perspectivas sobre carreiras, trajetórias, histórias de vida e itinerários intelectuais, particularmente em contextos urbanos.

\section{Felipe Magaldi é mestre em Antropologia pela UFF e doutorando em Antropo- logia Social no Museu Nacional/UFRJ.}


188 CAMPOS V.17 N.2 jul.dez.2016 